\title{
Análise da Estrutura Interna do Psicodiagnóstico Miocinético - PMK
}

\author{
Eni Ribeiro da Silva - Pontifícia Universidade Católica de Minas Gerais \\ Fabián J. M. Rueda - Universidade São Francisco
}

\begin{abstract}
Resumo
O objetivo do trabalho foi investigar a estrutura interna do Psicodiagnóstico Miocinético por meio da análise fatorial exploratória. A amostra foi composta por 300 sujeitos, de 18 a 61 anos, ambos sexos, residentes em Minas Gerais. Foram utilizadas as seis folhas do teste e a aplicação ocorreu em uma única sessão. A correção foi realizada com a régua, por avaliadores com experiência na utilização e ensino do instrumento. Os resultados mostraram a existência de sete fatores, dos quais apenas três foram similares à estrutura original do teste. Os coeficientes alfa variaram de 0,57 a 0,92 . Os traçados da dimensão Emotividade não se agruparam em um único fator. Os itens referentes aos "zigs" e "paralelas" se separaram nos fatores Dimensão Tensional e Predomínio Tensional. A estrutura original do teste não foi confirmada. São discutidas as fragilidades estruturais e das bases teóricas do PMK.
\end{abstract}

Palavras-chave: PMK, estrutura interna, validade, avaliação psicológica

\section{Analysis of Internal Structure of the Myokinetic Psychodiagnosis - PMK}

\begin{abstract}
The aim was to investigate the internal structure of Myokinetic Psychodiagnosis using exploratory factor analysis. The sample consisted of 300 subjects, 18-61 years of both genders from the state of Minas Gerais. The six test sheets were used and the application took place in a single session. The correction was performed with the a ruler, by evaluators experienced in the use and teaching of the instrument. The results showed the presence of seven factors, only three of which were similar to the original test structure. The alpha coefficients ranged from 0.57 to 0.92 . The tracings of Emotionality dimension were not grouped into a single factor. Items related to 'zigs' and 'parallel' separated the factors Tensional Dimension and Tensional Prevalence. The test original structure was not confirmed. We discussed the structural weakness and the theoretical bases of the PMK. Keywords: PMK, internal structure, validity, psychological assessment
\end{abstract}

\section{Análisis de Estructura Interna del Psicodiagnóstico Miocinético - PMK}

\section{Resumen}

El objetivo del trabajo fue investigar la estructura interna del Psicodiagnóstico Miokinético por medio del análisis factorial exploratorio. La muestra fue compuesta por 300 individuos, de 18 a 61 años, residentes en Minas Gerais y de ambos sexos. Fueron utilizadas las seis hojas del test y la aplicación fue realizada en una sesión única. La corrección fue utilizando la regla y por evaluadores que poseían experiencia tanto en utilizar como en enseñar el instrumento. Los resultados mostraron la presencia de siete factores, de los cuales apenas tres fueron semejantes a la estructura original del test. Los coeficientes alfa variaron de 0.57 a 0.92. Los trazos de la dimensión Emotividad no se agruparon en un factor único. Los ítems referentes a los 'zigs' y 'paralelas' se separaron en los factores Dimensión Tensional y Predominancia Tensional. La estructura original del test no fue confirmada. Son discutidas las fragilidades estructurales y las bases teóricas del PMK.

Palabras-clave: PMK, estructura interna, validez, evaluación psicológica

De acordo com Mira y López (1979), o PMK investiga características de personalidade por meio de cinco dimensões: Tônus Vital, Agressividade, Emotividade, Extra-Intratensão e Dimensão Tensional. Galland de Mira (1987) acrescentou mais uma dimensão às descritas por Mira y López, o Predomínio Tensional, além de renomear a dimensão Extra-Intratensão para Reação Vivencial. O autor considera que, a partir das seis dimensões, o PMK avalia diferentes traços de personalidade, agrupando setenta e seis traçados, a metade realizada com a mão direita (dominante para os destros) e metade com a mão esquerda (dominada).

Desde sua apresentação à comunidade científica, em 1939, o PMK passou a ser utilizado em países como
Espanha, França, Argentina, Uruguai, dentre outros; abrangendo, por exemplo, a avaliação de pacientes psiquiátricos e em processos seletivos (Quintela, 1977). No Brasil, foi amplamente utilizado em diversos contextos desde a década de 1940 até o ano de 2012, momento no qual o teste obteve parecer desfavorável para sua utilização por parte da Comissão Consultiva do Sistema de Avaliação Testes Psicológicos do Conselho Federal de Psicologia - CFP (Conselho Federal de Psicologia, 2012).

Com o objetivo de atender à Resolução 002/2003 do CFP (CFP, 2003), que determina a avaliação periódica das qualidades psicométricas dos testes psicológicos, o PMK passou por um processo de avaliação, 
que se iniciou no ano de 2009 e foi concluída no dia 15 de maio de 2012. Na ocasião, foi considerado desfavorável por não apresentar os requisitos mínimos exigidos para que o teste fosse considerado válido para uso profissional (Conselho Federal de Psicologia, 2012). De acordo com a comissão consultiva do CFP, o teste não apresentou uma fundamentação teórica consistente, impossibilitando a compreensão de sua relação entre as emoções e os movimentos musculares. Ainda, as pesquisas sobre evidências de validade e precisão foram consideradas insuficientes, não permitindo avaliar se o teste mede realmente o que se propõe medir.

Após um período de dois anos, em 2014, a quinta edição do manual do PMK foi lançada, após aprovação do Conselho Federal de Psicologia, que considerou que o material apresentado nesse manual atendia aos requisitos solicitados, referentes à validade, precisão e fundamentação teórica. Desse modo, o PMK encontra-se, no momento, com parecer favorável para uso profissional.

No que tange à primeira edição brasileira do manual do PMK, publicada em 1987, verifica-se a existência de 87 referências que se referem à utilização do teste em diversos contextos. Contudo, delas, apenas quatro estão relacionadas à validade do instrumento (Bessa, 1952; Bessa \& Schwarztein, 1951; Mira y López, 1951; Rennes, 1965).

Das pesquisas mencionadas, em apenas uma (Rennes, 1965) houve preocupação de investigar a estrutura interna do PMK. O autor realizou uma análise fatorial do PMK com uma amostra de 200 sujeitos do sexo masculino. A extração dos fatores foi realizada segundo o método centrado de Thurstone e, após a adaptação do número de fatores para a análise Varimax, foi realizada a análise fatorial com 80 variáveis do PMK e foram encontrados dez fatores, sendo eles: fator 1 : Comprimentos lineares dos zigue-zagues; fator 2: Comprimento lineares das paralelas; fator 3: Ângulos dos ziguezagues egocífugos; fator 4: DPs dos zigue-zagues; fator 5: DPs dos Us; fator 6: DPs e DSh dos lineogramas; fator 7: DPv dos lineogramas, círculos, cadeias e Us; fator 8: DPh dos lineogramas, DSs dos lineogramas, das paralelas e dos Us e DSv dos Us referentes à mão esquerda; fator 9: DPh dos lineogramas, DSs das paralelas e DSv dos Us relativos à mão direita; fator 10: DSv dos lineogramas e círculos e DSs dos lineogramas, todos referentes à mão direita.

Rennes (1965) evidenciou a discordância existente entre os resultados da análise fatorial realizada e o sistema interpretativo de Mira y López, seja por excesso ou por falta de fatores que excluíam a possibilidade de uma interpretação diferenciada. Contudo, o autor salientou a necessidade de que esses resultados fossem confirmados em outros estudos, sobretudo, porque a amostra foi composta somente por homens franceses, sendo necessário ampliá-la.

Como o PMK foi amplamente utilizado desde os anos 1940 e apenas uma pesquisa sobre sua estrutura interna foi relatada no manual original, buscou-se verificar a existência de pesquisas atuais que investigaram seus parâmetros psicométricos, com especial ênfase na sua estrutura interna. Uma revisão da literatura nas bases de dados Lilacs, Google Acadêmico, SciElo, Bireme, BVS-Psi, Psycoinfo e Portal Capes, com as palavras "PMK", "validade", "precisão" e "estrutura interna", com data posterior a 1987, mostrou a existência de nove trabalhos, sendo eles de Bardella, Costa, Esteves e Alves (2003), Baumgartl (2004), Martinez (2002), Ral, Sanzano e Martinez (2005); Sisto (2010), Tous, Viadé e Muiños (2006, 2007), Vasconcelos (2010) e, recentemente, Pasquali e Tróccoli (2014). Dos estudos mencionados, Bardella et al. (2003) investigaram aspectos relativos à precisão do PMK, e Sisto (2010) fez uma análise das informações contidas no manual do teste, sem realizar uma pesquisa empírica. O restante dos trabalhos investigou a estrutura interna do PMK e serão apresentados na sequência, em ordem cronológica.

Martinez (2002) realizou uma análise fatorial da versão digitalizada do PMK e comparou as cinco dimensões propostas por Mira y López (1951) com as seis dimensões propostas por Galland de Mira (1987). Participaram 449 universitários, ambos os sexos e maiores de idade. Após obter as variáveis quantitativas, por meio de um software de correção, o autor realizou uma análise fatorial confirmatória (AFC), primeiramente com toda a amostra e, posteriormente, separada por sexos. Os resultados revelaram um ajuste adequado para quatro das cinco dimensões propostas por Mira y López (Agressividade, Intra-Extratensão, Tônus vital e Emotividade). Contudo, a dimensão de Excitação e Inibição revelou um ajuste pobre, não havendo homogeneidade entre as variáveis que a comporiam. Os pesos fatoriais revelaram que das 14 variáveis dessa dimensão, oito tiveram um peso fatorial dentro do intervalo de $0,70 \mathrm{e}$ 0,80 e as outras seis dentro do intervalo de 0,44 e 0,45 . Esses dados sugeriram que as 14 variáveis da dimensão Excitação e Inibição formariam, pelo menos, dois fatores distintos. Já em relação às seis dimensões propostas por Galland de Mira (1987), metade delas apresentou 
um ajuste pobre. $\mathrm{O}$ autor concluiu que, para análise do teste, poderiam ser considerados os fatores Agressividade, Tônus Vital, Emotividade e Intra e Extratensão de Mira y López (1951) e o fator de Impulsividade de Galland de Mira (1987).

$\mathrm{Na}$ pesquisa de Baumgartl (2004), participaram 79 funcionários de uma empresa de energia elétrica, ambos os sexos e maiores de idade. O estudo considerou cinco das seis dimensões medidas pelo teste (Tônus Vital, Agressividade, Reação Vivencial, Emotividade e Predomínio Tensional) e não foram incluídos os traçados relativos aos círculos e cadeias verticais. A autora realizou uma análise fatorial das medidas do PMK, utilizando o método de componentes principais com rotação Varimax e encontrou uma solução fatorial composta por oito fatores, sendo: fator 1: Reação Vivencial, fator 2: Tônus Vital, fator 3: Agressividade, fator 4: junção de fatores de Agressividade e Reação Vivencial; fator 5: Predomínio Tensional, fator 6: Reação Vivencial, fator 7: junção de indicadores de Agressividade e Predomínio Tensional; fator 8: junção dos indicadores de Emotividade e Predomínio Tensional. Embora essa estrutura não tenha confirmado a proposta do teste, a autora não teceu críticas sobre o significado de seu achado.

Utilizando apenas as medidas dos lineogramas do PMK digitalizado, Ral, Sanzano e Martinez (2005) realizaram uma pesquisa na Espanha com 1010 sujeitos, sendo 343 homens e 667 mulheres, com idade entre 16 e 60 anos. A análise fatorial apontou a existência de cinco dimensões, sendo que a primeira contemplou os itens relativos à Dimensão Tensional; a segunda agrupou os itens referentes à Agressividade; a terceira reuniu os itens da Emotividade e reação vivencial da mão direita; a quarta dimensão incluiu os mesmos itens da terceira, porém relativos à mão esquerda. Por fim, a última dimensão agregou os dados referentes ao Tônus Vital.

Com proposito similar e, também, utilizando os lineogramas da versão revisada e digitalizada do teste, Tous, Viadé e Muiños (2006) investigaram a estrutura fatorial do PMK. A amostra foi composta por 992 adultos universitários, com idades entre 19 e 58 anos. A análise fatorial exploratória foi realizada separadamente para homens e mulheres. Os autores identificaram cinco dimensões, que agruparam os mesmos itens em ambos os grupos, havendo apenas uma pequena diferença entre a variância explicada para homens $(57,92 \%)$ e mulheres (59,03\%). A estrutura fatorial foi idêntica à encontrada por Ral et al. (2005).
Posteriormente, e com o objetivo de confirmar a estrutura fatorial dos lineogramas, Tous, Viadé e Muiños (2007) realizaram um estudo com 311 homens e 528 mulheres, com idades entre 19 a 54 anos, utilizando o mesmo método do estudo anterior. Os resultados obtidos confirmaram a estrutura fatorial dos traçados dos lineogramas, obtendo-se as cinco dimensões anteriormente encontradas, sem distinção para os sexos. Os estudos realizados na Espanha encontraram uma estrutura fatorial semelhante entre eles, porém a configuração dos itens apresenta algumas discordâncias em relação à estrutura descrita por Mira y López, relativas à junção da emotividade com reação vivencial, formando dois fatores (mão esquerda e mão direita).

No Brasil, Vasconcelos (2010) realizou um estudo com duas amostras de soldados, sendo uma com 248 e outra com 671 participantes. A análise fatorial exploratória (AFE) encontrou resultados semelhantes em ambas as amostras, com itens relativos à Agressividade agrupando em um único fator. A Reação vivencial agrupou itens relativos à mão direita e mão esquerda, correspondendo a dois fatores distintos. Dimensão Tensional e Predomínio Tensional se dividiram em dois fatores, constituídos dos itens das paralelas, e outro dos itens relacionados aos zigue-zagues, para a amostra de 671 participantes. Na análise com amostra de 248 sujeitos, todos os itens de Dimensão Tensional de ambas as mãos e alguns itens do predomínio tensional dos zigue-zagues e paralelas foram agrupados, e os demais itens dessa dimensão misturaram-se com outros fatores. Os itens relativos à Emotividade se misturaram com itens da reação vivencial, separadamente para mão esquerda e mão direita, todos com carga fatorial negativa. Os itens do Tônus Vital foram agrupados, com exceção dos traçados das Escadas que se juntaram ao fator Agressividade, e os traçados dos lineogramas da mão esquerda que se reuniram com os de reação vivencial da mão direita. Um ponto importante a destacar é o fato de que as análises das duas amostras não encontraram uma solução fatorial semelhante, e ainda, a estrutura original do PMK não foi confirmada a partir dos dados do estudo, com nenhuma das amostras.

Também no Brasil, Pasquali e Tróccoli (2014) investigaram a estrutura interna do teste por meio da análise fatorial exploratória e confirmatória. A análise foi realizada com duas amostras, uma de 700 sujeitos, que contemplou dados relativos a cinco dimensões do teste (Tônus Vital, Agressividade, Dimensão Tensional, Predomínio Tensional e Reação Vivencial), composta por 64 itens do PMK, e outra em amostra com 200 
sujeitos, em que havia 28 itens relativos a duas dimensões do teste (Emotividade e Reação Vivencial). Nesse trabalho, diferentemente dos demais, foram confirmados os seis fatores descritos por Galland de Mira (1987). Contudo, analisando os dados apresentados, identificou-se que a permanência de um item na dimensão não seguiu alguns critérios comumente aceitos, por exemplo, apresentar carga fatorial de, no mínimo, 0,32 (Tabachnick \& Fidell, 2001). Com isso, as dimensões incluíram itens com cargas fatoriais muito baixas, o que pode representar uma estrutura não confiável.

Conforme as pesquisas de análise fatorial realizadas com o PMK, verifica-se grande dificuldade em se agrupar os fatores conforme descrito por Mira y López e Galland de Mira. Contudo, algumas semelhanças entre os achados nas pesquisas com a proposta no teste são relevantes. Os itens relativos à Emotividade não se agruparam em um só fator em nenhuma das pesquisas, mas sim, juntaram-se, na maioria dos casos, com o fator reação vivencial. A reação vivencial, por sua vez, dividiu-se em mão esquerda e mão direita, formando dois fatores distintos. A Agressividade e o Tônus Vital mostraram maior consistência no agrupamento dos itens. Por sua vez, o predomínio tensional e a Dimensão Tensional foram os fatores que mais se misturaram, ora com itens de outras dimensões, ora agrupando os itens de zigue-zagues e paralelas separadamente.

Desse modo, a estrutura fatorial do teste não se mostrou consistente, pelo contrário, o agrupamento dos itens nas dimensões se manteve instável, em todos os trabalhos, revelando a possível fragilidade estrutural do instrumento. Uma hipótese para esse fato é que os itens do teste podem não estar representando adequadamente o construto proposto em cada dimensão investigada, conforme a estrutura de seis dimensões defendida por Galland de Mira (1987) e Pasquali e Tróccoli (2014). Em outras palavras, é possível que itens que são considerados representantes de uma dimensão estejam relacionados a outra dimensão do teste, ou mesmo, a um construto ainda não identificado.

Como visto, a partir da análise das pesquisas realizadas com o PMK, algumas dúvidas necessitam ser esclarecidas. A principal se refere à estrutura interna do instrumento, uma vez que há registros de poucas pesquisas que contemplaram tal investigação, sendo que Baumgartl (2004) e Vasconcelos (2010), embora tenham realizado uma análise fatorial do PMK, não tiveram essa análise como foco principal de seus estudos. Vale salientar também que, embora Sisto (2010) tenha criticado as informações contidas no manual do
PMK de 2004, ele examinou de maneira sistematizada e minuciosa apenas os dados contidos nesse manual, ou seja, analisou o material sob uma perspectiva teórica, restringindo-se às informações disponíveis, sem, contudo, acessar as pesquisas referenciadas no manual. De acordo com Pasquali e Tróccoli (2014, p. 31) “as conclusões de Sisto (2010) não podem ser consideradas como pertinentes às questões de validade do teste PMK, e sim à qualidade do que foi apresentado na versão 2004 do seu manual".

Assim sendo, torna-se crucial investigar a estrutura interna do PMK, estabelecendo uma interlocução com os achados de outros pesquisadores, visto que os resultados aqui apresentados são discordantes no que se refere à proposta teórica do PMK que contempla seis dimensões. Ou seja, é relevante saber se as dimensões ou os fatores medidos pelo teste estão adequados. Quando Mira y López (1979), Galland de Mira (1987) e Pasquali e Tróccoli (2014) relatam que, por meio do PMK podem ser aferidos construtos relacionados a Tônus Vital, Emotividade, Reação Vivencial, Predomínio Tensional, Dimensão Tensional e Agressividade, tais aspectos estão mesmo sendo medidos pelo instrumento? Com base nas questões aqui apresentadas, esta pesquisa objetivou investigar a estrutura interna do PMK, por meio da análise fatorial exploratória.

\section{Método}

\section{Participantes}

Participaram da pesquisa 300 sujeitos, residentes em Belo Horizonte e região metropolitana. A idade dos participantes variou de 18 a 66 anos, com média de $26,99(D P=8,36)$. A maioria $(77,7 \%)$ era do sexo feminino, com níveis de escolaridade diversos, desde ensino fundamental incompleto até nível superior completo e pós- graduação. A amostra foi por conveniência, e composta por $95,7 \%$ de participantes destros.

\section{Instrumentos}

Psicodiagnóstico Miocinético - PMK (Galland de Mira, 1987)

O PMK se baseia na Teoria Motriz da Consciência, que preconiza que toda ação ou reação do sujeito é precedida por uma mudança do tônus postural. $\mathrm{O}$ instrumento avalia características estruturais e reacionais a partir do princípio da dissociação miocinética, que afirma existirem diferenças entre os dois hemisférios cerebrais. O teste é realizado com lápis e papel, sendo necessária uma mesa específica para a aplicação. 
Também são utilizados os cartões de cobertura e o anteparo, que servem para cobrir a visão do sujeito durante sua aplicação. É composto por seis folhas com exemplos impressos, sendo que o candidato deve iniciar a tarefa vendo e, posteriormente, continuar o traçado sem o controle visual, ou seja, sem enxergar o que está fazendo. A aplicação não tem tempo limite, mas a média de duração é em torno de sessenta minutos. $\mathrm{O}$ teste pode ser aplicado em sujeitos de todos os níveis de escolaridade, inclusive analfabetos. No entanto, sugere-se que ele seja aplicado em sujeitos a partir dos oito anos de idade. O PMK avalia seis dimensões, com polaridades distintas, sendo eles: Tônus Vital (elação/depressão), Agressividade (heteroagressividade/autoagressividade), Dimensão Tensional, Reação Vivencial (extratensão/intratensão), Predomínio Tensional (impulsividade/rigidez) e por fim Emotividade. Ao todo, são avaliados 76 traçados para compor as dimensões mencionadas. A execução do PMK requer uma postura adequada, que inclui a coluna ereta, sem encostar-se ao espaldar da cadeira, e os pés devem estar apoiados no chão, sem cruzá-los. O lápis deve ser pego pelo meio, na posição vertical, e os movimentos devem ser realizados com todo o braço. $\mathrm{O}$ sujeito trabalha ora com a mão direita, ora com a mão esquerda e, por vezes, com as duas mãos ao mesmo tempo. Os estudos de evidências de validade e precisão do instrumento carecem, em muitos casos, de dados estatísticos, uma vez que as pesquisas citadas no manual são inconclusivas e, de maneira geral, foram realizadas com número reduzido de participantes, com pouca clareza em relação aos procedimentos e resultados, impossibilitando a replicação por outros pesquisadores.

\section{Procedimentos}

Enquanto se aguardava a aprovação do projeto pelo Comitê de Ética em Pesquisa, realizou-se um treinamento com a equipe responsável pela coleta dos dados, que foi composta por seis psicólogas com experiência na aplicação do PMK e 14 estudantes de Psicologia que haviam sido monitores do Laboratório de Avaliação Psicológica de uma instituição de ensino superior em Psicologia. O treinamento teve duração de um mês. Após a aprovação do projeto (CAAE: 09550212700005514), foi realizado o contato com os sujeitos que foram convidados a participar voluntariamente da pesquisa. A coleta dos dados ocorreu no período de novembro de 2012 a outubro de 2013. Antes da aplicação, os participantes foram esclarecidos sobre os objetivos da pesquisa, seus direitos como participantes, e foi solicitada a assinatura do Termo de Consentimento Livre e Esclarecido. A aplicação do PMK ocorreu na Clínica de Psicologia e no Laboratório de Avaliação Psicológica de uma instituição de ensino superior.

A aplicação foi realizada individualmente e teve duração de aproximadamente uma hora. Foram aplicadas as seis folhas que compõem o teste numa única sessão, sem intervalos, e respeitando as instruções contidas no manual. Antes de se proceder a aplicação, os participantes responderam a um questionário que versava sobre uso de medicamentos, patologias ou condições físicas e psicológicas no momento da realização do teste, seguindo as orientações do manual.

O material coletado foi avaliado quanto a sua aplicação por dois pesquisadores com expertise em aplicação e correção do PMK, com o objetivo de verificar a correta aplicação de todos os traçados, inclusive aqueles realizados com a mesa na posição vertical (cadeias verticais e círculos), com o intuito de evitar possíveis erros que pudessem comprometer os resultados da pesquisa. A mensuração do teste foi manual, utilizando a régua para avaliação dos desvios em milímetros e, em seguida, os valores encontrados foram transformados em tetrons (refere-se a $1 / 4$ do desvio padrão) conforme tabela geral de amostras dos sexos masculino e feminino, e considerando a mão dominante de cada participante. Da mesma forma, todos os protocolos foram corrigidos pelos dois profissionais a fim de evitar possíveis erros de correção e de interpretação dos tetrons. Assim, houve um grande rigor metodológico no sentido de evitar qualquer ocorrência que pudesse interferir nos resultados desta pesquisa. Os protocolos que apresentaram erros de aplicação (aproximadamente $7 \%$, no início da coleta de dados, foram retirados da amostra.

\section{Análise dos Dados}

A estrutura interna foi avaliada pela análise fatorial pelos principais eixos fatoriais, considerando a anormalidade na distribuição da amostra, com rotação Oblimin. A adequação da amostra foi analisada pelo coeficiente Kaiser-Meyer-Olkin (KMO) e pelo teste de esfericidade de Barttlet. Posteriormente, foram calculados os índices de precisão de cada fator pelo coeficiente alfa, assim como a correlação item-fator e o valor de alfa, caso o item fosse deletado. Com base nesses resultados, uma nova análise fatorial foi conduzida, mantendo os mesmos critérios iniciais. As análises foram realizadas utilizando o programa estatístico SPSS 20.0. 


\section{Resultados}

Antes de proceder à análise fatorial, foi avaliado se era adequado tal procedimento, considerando os dados dos quais se dispunha. Para isso, inicialmente foi analisada a adequação amostral de Kaiser-Meyer-Olkin (KMO) e a prova de esfericidade de Bartlett. De acordo com Pasquali (2003), coeficientes de KMO acima de 0,60 são aceitáveis; acima de 0,70 são moderados e acima de 0,80 são excelentes. Por sua vez, Hair, Anderson, Tatham e Black (2005) afirmam que resultados significativos no teste de esfericidade Barttlet indicam a existência de correlações significativas na matriz de dados, e valores com níveis de significância $p<0,05$ indicam que a matriz é fatorável. Nesse sentido, o resultado do KMO foi igual a 0,67 , e a prova de esfericidade de Bartlett foi estatisticamente significativa $X^{2}(2850)=$ 13607,$67 ; p<0,001$. Por esse resultado, ambos os critérios sustentaram a fatorabilidade dos dados.

Dando seguimento, foi estabelecido como parâmetro para a permanência do item na escala uma carga fatorial superior a 0,32 , seguindo recomendações de Tabachnick e Fidell (2001). Os autores consideram esse valor mínimo para aceitar o item, uma vez que ele corresponde a $10 \%$ da variância explicada, desde que esses itens não tenham cargas fatoriais iguais ou superiores a
0,20 em outros fatores além daquele no qual apresentou carga de 0,32 ou superior.

Para definir o número de fatores, foram utilizados dois critérios: o teste Scree de Cattell e a análise paralela de Horn. É importante destacar que o critério de Guttman-Kaiser ou da raiz latente (autovalores superiores a 1,0) não foi considerado para a decisão de retenção de fatores, uma vez que esse método tende a superestimar o número de fatores, principalmente quando o tamanho da amostra é pequeno.

De acordo com a consideração inicial, pelo critério de carga fatorial de 0,32 , não permaneceram na análise sete traçados, quais sejam, DSv cadeias verticais descendentes da mão esquerda, DSv dos lineogramas das mãos direita e esquerda, DSv dos círculos das mãos direita e esquerda (todos eles relacionados ao fator Emotividade), assim como DSs paralelas egocípetas da mão direita e DSs zig egocífugo da mão direita (ambos relacionados ao fator Reação vivencial). Com a retirada deles, a análise fatorial foi realizada com 69 traçados. Os resultados do scree-plot podem ser observados na Figura 1.

Considerando o critério do scree-plot, observou-se a presença de sete fatores como sendo a mais adequada, uma vez que no gráfico eles se encontram acima da linha reta formada. Por sua vez, a análise paralela

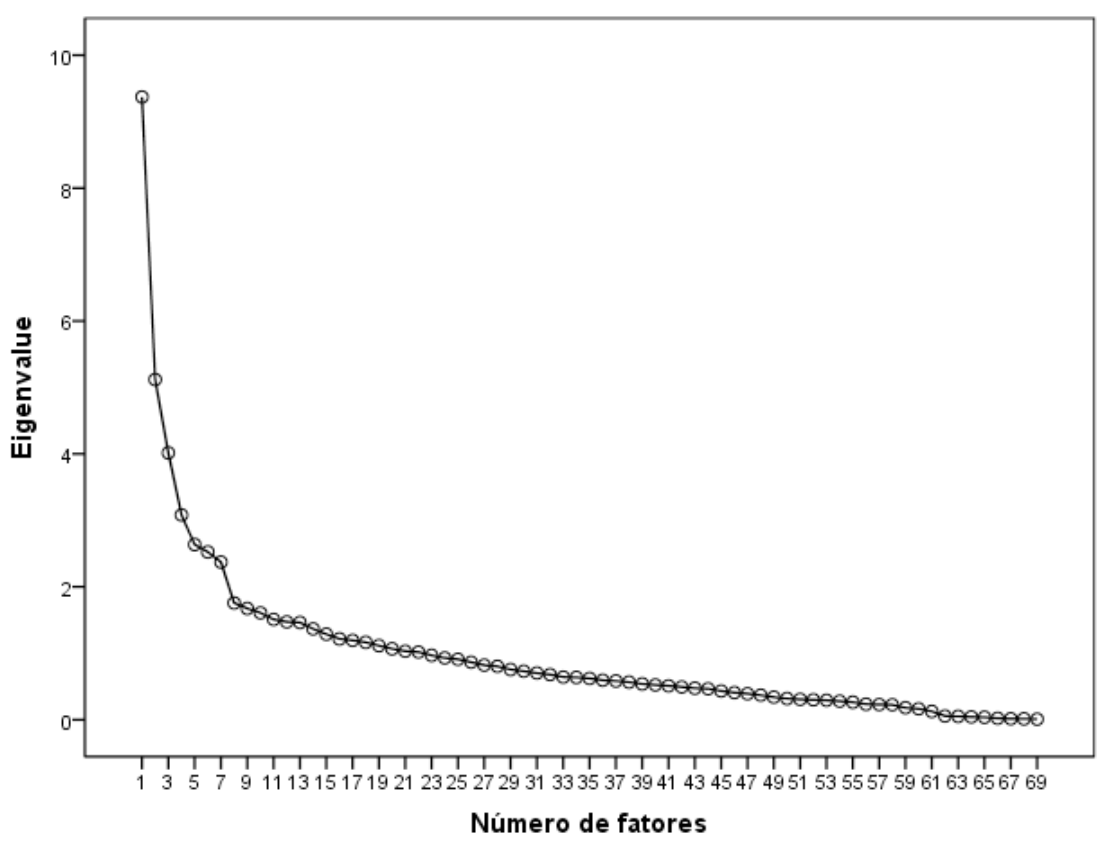

Figura 1. Gráfico de sedimentação para os traçados do PMK. 
de Horn também indicou a existência de sete fatores, após uma base em 1.000 amostras aleatórias. Com base nesses aspectos, procedeu-se à avaliação dos traçados em uma estrutura de sete fatores, como apresentado na Tabela 1.
O agrupamento dos traçados do PMK mostrou alguns fatores bem definidos. Por exemplo, os traçados referentes à "Dimensão Tensional" foram claramente separados nos fatores 1 e 2 , sendo que no primeiro ficaram agrupados todos os traçados

Tabela 1

Cargas Fatoriais por meio da Análise Fatorial pelos Principais Eixos Fatoriais com Rotação Oblimin

\begin{tabular}{|c|c|c|c|c|c|c|c|}
\hline Fatores & 1 & 2 & 3 & 4 & 5 & 6 & 7 \\
\hline Dimensão tensional mão direita - zig máx. egocípeto & 0,88 & & & & & & \\
\hline Dimensão tensional mão direita - zig máx. egocífugo & 0,86 & & & & & & \\
\hline Dimensão tensional mão esquerda - zig máx. egocípeto & 0,84 & & & & & & \\
\hline Dimensão tensional mão direita - zig min. egocífugo & 0,78 & & & & & & \\
\hline Dimensão tensional mão direita - zig min. egocípeto & 0,77 & & & & & & \\
\hline Dimensão tensional mão esquerda - zig máx. egocífugo & 0,76 & & & & & & \\
\hline Dimensão tensional mão esquerda - zig min. egocípeto & 0,70 & & & & & & \\
\hline Dimensão tensional mão esquerda - zig min. egocífugo & 0,69 & 0,37 & & & & & \\
\hline Predomínio tensional mão direita - diferença zig egocífugo & 0,62 & & & & & & \\
\hline Predomínio tensional mão esquerda - diferença zig egocípeto & 0,56 & & & & & & \\
\hline Predomínio tensional mão esquerda - diferença zig egocífugo & 0,55 & & & & & 0,33 & \\
\hline Predomínio tensional mão direita - diferença zig egocípeto & 0,49 & & & & & 0,36 & \\
\hline Dimensão tensional mão esquerda - paralela min. egocípeta & & 0,83 & & & & & \\
\hline Dimensão tensional mão direita - paralela min. egocípeta & & 0,79 & & & & & \\
\hline Dimensão tensional mão direita - paralela min. egocífuga & & 0,78 & & & & & \\
\hline Dimensão tensional mão esquerda - paralela min. egocífuga & & 0,78 & & & & & \\
\hline Dimensão tensional mão direita - paralela máx. egocípeta & & 0,78 & & & & & \\
\hline Dimensão tensional mão esquerda - paralela máx. egocípeta & & 0,76 & & & & & \\
\hline Dimensão tensional mão esquerda - paralela máx. egocífuga & & 0,73 & & & & 0,37 & \\
\hline Dimensão tensional mão direita - paralela máx. egocífuga & & 0,71 & & & & & \\
\hline Dimensão tensional mão direita - lineograma & & 0,62 & & & & & \\
\hline Dimensão tensional mão esquerda - lineograma & & 0,62 & & & & & \\
\hline Agressividade mão direita DSh - lineograma & & & 0,60 & & & & \\
\hline Agressividade mão esquerda DPs - cadeias & & & 0,59 & & & & \\
\hline Agressividade mão direita DPs - paralelas & & & 0,59 & & & & \\
\hline Agressividade mão direita DPs - zig-zag & & & 0,57 & & & & \\
\hline Agressividade mão esquerda DPs - lineograma & & & 0,55 & & & & \\
\hline Agressividade mão direita DPs - cadeias & & & 0,55 & & & & \\
\hline Agressividade mão direita DPs - Us & & & 0,54 & & & & \\
\hline Agressividade mão direita DPs - lineograma & & & 0,54 & & & & \\
\hline Agressividade mão esquerda DPs - zig-zag & & & 0,54 & & & & \\
\hline Agressividade mão esquerda DSh - lineograma & & & 0,54 & & & & \\
\hline Agressividade mão esquerda DPs - Us & & & 0,54 & & & & \\
\hline Agressividade mão esquerda DPs - paralelas & & & 0,50 & & & & \\
\hline
\end{tabular}


Tabela 1

Cargas Fatoriais por meio da Análise Fatorial pelos Principais Eixos Fatoriais com Rotação Oblimin (Continuação)

\begin{tabular}{|c|c|c|c|c|c|c|c|}
\hline Fatores & 1 & 2 & 3 & 4 & 5 & 6 & 7 \\
\hline Tônus vital mão esquerda $\mathrm{DPv}$ - círculos & & & & 0,66 & & & \\
\hline Tônus vital mão direita $\mathrm{DPv}$ - Us & & & & 0,62 & & & \\
\hline Tônus vital mão esquerda $\mathrm{DPv}$ - lineograma & & & & 0,62 & & & \\
\hline Tônus vital mão direita $\mathrm{DPv}$ - lineograma & & & & 0,61 & & & \\
\hline Tônus vital mão esquerda $\mathrm{DPv}$ - Us & & & & 0,60 & & & \\
\hline Tônus vital mão direita $\mathrm{DPv}$ - círculos & & & & 0,59 & & & \\
\hline Tônus vital mão esquerda $\mathrm{DPv}$ - cadeias & & & & 0,43 & & & \\
\hline Tônus vital mão direita $\mathrm{DPv}$ - cadeias & & & & 0,43 & & & \\
\hline Tônus vital mão direita $\mathrm{DPv}$ - escadas & & & & 0,35 & & & \\
\hline Tônus vital mão esquerda $\mathrm{DPv}$ - escadas & & & & 0,33 & & & \\
\hline Reação vivencial mão esquerda DSs - Us & & & & & 0,61 & & \\
\hline Reação vivencial mão esquerda DSs - paralelas egocífugo & & & & & 0,60 & & \\
\hline Reação vivencial mão esquerda $\mathrm{DPh}$ - lineograma & & & & & 0,60 & & \\
\hline Reação vivencial mão esquerda DSs - cadeias sag. egocífugo & & & & & 0,57 & & \\
\hline Reação vivencial mão esquerda DSs - paralelas egocípeto & & & & & 0,53 & & \\
\hline Reação vivencial mão esquerda DSs - lineograma & & & & & 0,49 & & \\
\hline Reação vivencial mão esquerda DSs - cadeias sag. egocípeto & & & & & 0,47 & & \\
\hline Emotividade mão esquerda DSv - cadeias vert. ascendente & & & & & $-0,44$ & & \\
\hline Reação vivencial mão esquerda DSs - zig egocífugo & & & & & 0,39 & & \\
\hline Reação vivencial mão esquerda DSs - zig egocípeto & & & & & 0,33 & & \\
\hline Emotividade mão esquerda DSv - Us & & & & & $-0,32$ & & \\
\hline Predomínio tensional mão direita - diferença paralela egocífuga & & & & & & 0,59 & \\
\hline $\begin{array}{l}\text { Predomínio tensional mão esquerda - diferença paralela } \\
\text { egocífuga }\end{array}$ & & & & & & 0,57 & \\
\hline Predomínio tensional mão direita - diferença paralela egocípeta & & & & & & 0,54 & \\
\hline $\begin{array}{l}\text { Predomínio tensional mão esquerda - diferença paralela } \\
\text { egocípeta }\end{array}$ & & & & & & 0,40 & \\
\hline Emotividade mão direita DSv - Us & & & & & & 0,37 & \\
\hline Emotividade mão direita DSv - cadeias vert. ascendente & & & & & & 0,33 & \\
\hline Reação vivencial mão direita DSs - Us & & & & & & & 0,64 \\
\hline Reação vivencial mão direita DSs - lineograma & & & & & & & 0,64 \\
\hline Reação vivencial mão direita DSs - cadeias sag. egocípeto & & & & & & & 0,57 \\
\hline Reação vivencial mão direita DSs - cadeias sag. egocífugo & & & & & & & 0,56 \\
\hline Reação vivencial mão direita DSs - DPh lineograma & & & & & & & 0,47 \\
\hline Emotividade mão direita DSv - cadeias vert. descendente & & & & & & & 0,41 \\
\hline Reação vivencial mão direita DSs - zig egocípeto & & & & & & & 0,37 \\
\hline Reação vivencial mão direita DSs - paralelas egocífugo & & & & & & & 0,34 \\
\hline Quantidade de traçados & 12 & 10 & 12 & 10 & 11 & 6 & 8 \\
\hline Autovalor & 9,37 & 5,12 & 4,02 & 3,08 & 2,64 & 2,53 & 2,37 \\
\hline Variância explicada (\%) & 13,58 & 7,42 & 5,82 & 4,47 & 3,82 & 3,66 & 3,44 \\
\hline Total de Variância explicada (\%) & & & & 42,20 & & & \\
\hline
\end{tabular}


referentes aos "zigs" e no fator 2 todos os traçados restantes. Vale destacar que no fator 1 também foram agrupados os indicadores referentes à diferença dos "zigs" da dimensão "Predomínio Tensional". Por sua vez, o fator 2 foi formado exclusivamente por traçados da "Dimensão Tensional".

No que se refere aos fatores 3 e 4 , o primeiro agrupou todos os traçados da dimensão "Agressividade", enquanto o fator 4 reuniu todos do "Tônus Vital". Dessa forma, os traçados desses fatores se mostraram alinhados com a teoria do teste.

Já os fatores 5, 6 e 7, embora tenham apresentado uma estrutura aparentemente lógica, em todos foram incluídos traçados referentes à Emotividade. No caso do fator 5, foram agrupados todos os traçados de Reação Vivencial da mão esquerda, mais os traçados das cadeias verticais ascendentes e Us verticais, ambos da mão esquerda, da dimensão "Emotividade", que, por sua vez, apresentaram cargas fatoriais negativas. O fator 7 também agrupou todos os traçados da "Reação Vivencial", porém referentes à mão direita, além do traçado "cadeias verticais descendentes" da "Emotividade". Por fim, o fator 6 congregou a "diferença das paralelas egocífugas e egocípetas" de ambas as mãos, da dimensão "Predomínio Tensional", mais dois traçados relacionados com a "Emotividade", quais sejam, "Us" e "cadeias verticais ascendentes" da mão direita.

É importante destacar que, embora a recomendação de Tabachnick e Fidell (2001) não tenha sido evidenciada em quatro traçados, foi observado que eles apresentaram uma carga fatorial bem mais elevada em um dos fatores, assim como a existência de justificativa teórica plausível. Dessa forma, decidiu-se proceder às análises com os 69 traçados descritos.

$\mathrm{Na}$ sequência, foram calculados os índices de precisão pelo coeficiente alfa. Ainda, foi verificada a correlação item-fator e o valor do alfa caso o item fosse deletado. Esses resultados são apresentados na Tabela 2.

Pela Tabela 2, pode ser observado que os coeficientes alfa foram satisfatórios para os primeiros quatro fatores (superiores a 0,70 ), enquanto que no Fator 7 pode ser considerado aceitável $(\alpha=0,65)$. Já nos fatores 5 e 6 ele foi muito baixo $(0,52$ e 0,49 respectivamente), mostrando que metade deles se refere a erro. Analisando esses dois fatores, pode ser verificado que os quatro traçados (dois em cada fator), que se referem a "Emotividade", apresentaram valores de correlação item-fator inferiores a 0,20 , que é o mínimo indicado pelo American Institute for Research e pela Educational Tests
Services como indicador para considerar o item satisfatório. Considerando esses aspectos, optou-se por retirar os itens e rodar novamente a análise fatorial. Além disso, o traçado "Dsv - cadeias verticais descendentes", referente à "Emotividade" e localizado no fator 7, também foi retirado para a nova análise. Essa decisão foi adotada considerando que foi o único traçado da dimensão "Emotividade" que permaneceu nas análises, assim como a correlação item-fator, que embora não tenha sido inferior a 0,20 , foi bastante baixa $(0,22)$.

Cabe destacar que, na nova análise fatorial realizada, foram mantidos os mesmos critérios para permanência dos itens e número de fatores. Assim sendo, o resultado do KMO foi igual a 0,68 , e a prova de esfericidade de Bartlett foi estatisticamente significativa $X^{2}(2016)=12607,21 ; p<0,001$. A Tabela 3 apresenta as cargas fatoriais assim como os autovalores, a variância explicada e os coeficientes alfa.

Considerando a nova análise apresentada na Tabela 3, pode-se observar que os fatores mantiveram a estrutura inicialmente apresentada. Além disso, os coeficientes de precisão dos fatores 5 e 6 , que inicialmente foram inadequados, aumentaram substancialmente. Nesse sentido, o fator 5 apresentou um valor aceitável $(0,68)$, enquanto o fator 6 apresentou um valor de 0,57 que, mesmo não atingindo o nível recomendado, aumentou consideravelmente, especialmente considerando o pequeno número de itens que ficaram alocados nesse fator. Ainda, o fator 7 manteve um coeficiente aceitável, porém, com uma leve diminuição em relação à análise inicial. A variância total explicada aumentou, passando para $44,30 \%$.

\section{Discussão}

A discussão deste trabalho será realizada sob dois focos. O primeiro, considerando a estrutura interna alcançada e comparando-a com dados oriundos da literatura. O segundo objetivará apresentar questionamentos à própria técnica que, aparentemente, não se sustenta desde a sua própria fundamentação teórica.

No que se refere à estrutura interna evidenciada, a análise fatorial exploratória revelou a existência de sete fatores e, destes, três distintos e independentes entre si, sendo eles: Tônus Vital, Agressividade, Reação Vivencial. A dimensão Emotividade não se agrupou em um único fator, pois se misturou com reação vivencial e predomínio tensional dos itens das paralelas, contrariando a proposta teórica de Mira y López (1979), Galland de Mira (1987) e Pasquali e Tróccoli (2014). 
Tabela 2

Coeficientes Alfa, Correlação Item-Fator e a se o Item Fosse Deletado, para os Fatores Encontrados no PMK Fator $1(\alpha=0,92)$

\begin{tabular}{lcc}
\hline Traçado & $\begin{array}{c}\text { Correlação item-fator } \\
\text { Dimensão tensional mão direita - zig máx. egocípeto }\end{array}$ & $\begin{array}{c}\alpha \text { se item fosse } \\
\text { deletado }\end{array}$ \\
Dimensão tensional mão direita - zig máx. egocífugo & 0,86 & 0,91 \\
Dimensão tensional mão esquerda - zig máx. egocípeto & 0,85 & 0,91 \\
Dimensão tensional mão direita - zig min. egocífugo & 0,82 & 0,91 \\
Dimensão tensional mão direita - zig min. egocípeto & 0,75 & 0,91 \\
Dimensão tensional mão esquerda - zig máx. egocífugo & 0,69 & 0,91 \\
Dimensão tensional mão esquerda - zig min. egocípeto & 0,78 & 0,91 \\
Dimensão tensional mão esquerda - zig min. egocífugo & 0,66 & 0,92 \\
Predomínio tensional mão direita - diferença zig egocífugo & 0,69 & 0,92 \\
Predomínio tensional mão esquerda - diferença zig egocípeto & 0,56 & 0,92 \\
Predomínio tensional mão esquerda - diferença zig egocífugo & 0,47 & 0,92 \\
Predomínio tensional mão direita - diferença zig egocípeto & 0,52 & 0,92 \\
\hline
\end{tabular}

Fator $2(\alpha=0,91)$

\begin{tabular}{lcc}
\hline \multicolumn{1}{c}{ Traçado } & Correlação item-fator & $\begin{array}{c}\alpha \text { se o item fosse } \\
\text { deletado }\end{array}$ \\
\hline Dimensão tensional mão esquerda - paralela min. egocípeta & 0,79 & 0,89 \\
Dimensão tensional mão direita - paralela min. egocípeta & 0,71 & 0,90 \\
Dimensão tensional mão direita - paralela min. egocífuga & 0,71 & 0,90 \\
Dimensão tensional mão esquerda - paralela min. egocífuga & 0,74 & 0,90 \\
Dimensão tensional mão direita - paralela máx. egocípeta & 0,66 & 0,90 \\
Dimensão tensional mão esquerda - paralela máx. egocípeta & 0,73 & 0,90 \\
Dimensão tensional mão esquerda - paralela máx. egocífuga & 0,69 & 0,90 \\
Dimensão tensional mão direita - paralela máx. egocífuga & 0,71 & 0,88 \\
Dimensão tensional mão direita - lineograma & 0,59 & 0,91 \\
Dimensão tensional mão esquerda - lineograma & 0,60 & 0,91 \\
\hline
\end{tabular}

\begin{tabular}{lcc}
\hline \multicolumn{1}{c}{ Traçado } & Fator 3 $(\alpha=0,81)$ & \\
\hline \multicolumn{1}{c}{ Agressividade mão direita DSs - lineograma Dsl } & Correlação item-fator & $\begin{array}{c}\alpha \text { se o item fosse } \\
\text { deletado }\end{array}$ \\
Agressividade mão esquerda DPs - cadeias & 0,53 & 0,79 \\
Agressividade mão direita DPs - paralelas & 0,44 & 0,80 \\
Agressividade mão direita DPs - zig-zag & 0,50 & 0,79 \\
Agressividade mão esquerda DPs - lineograma & 0,52 & 0,79 \\
Agressividade mão direita DPs - cadeias & 0,40 & 0,80 \\
Agressividade mão direita DPs - Us & 0,42 & 0,80 \\
Agressividade mão direita DPs - lineograma & 0,47 & 0,80 \\
Agressividade mão esquerda DPs - zig-zag & 0,48 & 0,80 \\
Agressividade mão esquerda DSs - lineograma & 0,48 & 0,80 \\
Agressividade mão esquerda DPs - Us & 0,45 & 0,80 \\
Agressividade mão esquerda DPs - paralelas & 0,47 & 0,80 \\
\hline
\end{tabular}


Tabela 2

Coeficientes Alfa, Correlação Item-Fator e a se o Item Fosse Deletado, para os Fatores Encontrados no PMK (Continuação)

\begin{tabular}{lcc}
\hline \multicolumn{1}{c}{ Traçado } & Fator 4 $(\alpha=0,75)$ & \\
\hline Tônus vital mão esquerda DPv - círculos & Correlação item-fator & $\begin{array}{c}\alpha \text { se o item fosse } \\
\text { deletado }\end{array}$ \\
Tônus vital mão direita DPv - Us & 0,52 & 0,71 \\
Tônus vital mão esquerda DPv - lineograma & 0,49 & 0,71 \\
Tônus vital mão direita DPv - lineograma & 0,45 & 0,72 \\
Tônus vital mão esquerda DPv - Us & 0,44 & 0,72 \\
Tônus vital mão direita DPv - círculos & 0,44 & 0,72 \\
Tônus vital mão esquerda DPv - cadeias & 0,46 & 0,72 \\
Tônus vital mão direita DPv - cadeias & 0,33 & 0,74 \\
Tônus vital mão direita DPv - escadas & 0,38 & 0,73 \\
Tônus vital mão esquerda DPv - escadas & 0,29 & 0,74 \\
\hline
\end{tabular}

Fator $5(\alpha=0,52)$

\begin{tabular}{|c|c|c|}
\hline Traçado & Correlação item-fator & $\begin{array}{c}\alpha \text { se o item fosse } \\
\text { deletado }\end{array}$ \\
\hline Reação vivencial mão esquerda DSs - Us & 0,41 & 0,45 \\
\hline Reação vivencial mão esquerda DSs - paralelas egocífugo & 0,37 & 0,47 \\
\hline Reação vivencial mão esquerda $\mathrm{DPh}$ - lineograma & 0,32 & 0,47 \\
\hline Reação vivencial mão esquerda DSs - cadeias sag. egocífugo & 0,33 & 0,46 \\
\hline Reação vivencial mão esquerda DSs - paralelas egocípeto & 0,34 & 0,47 \\
\hline Reação vivencial mão esquerda DSs - lineograma & 0,29 & 0,49 \\
\hline Reação vivencial mão esquerda DSs - cadeias sag. egocípeto & 0,37 & 0,46 \\
\hline Emotividade mão esquerda DSv - cadeias vert. ascendente & $-0,24$ & 0,61 \\
\hline Reação vivencial mão esquerda DSs - zig egocífugo & 0,24 & 0,49 \\
\hline Reação vivencial mão esquerda DSs - zig egocípeto & 0,20 & 0,51 \\
\hline Emotividade mão esquerda DSv - Us & $-0,20$ & 0,59 \\
\hline \multicolumn{3}{|l|}{ Fator $6(\alpha=0,49)$} \\
\hline Traçado & Correlação item-fator & $\begin{array}{c}\alpha \text { se o item fosse } \\
\text { deletado }\end{array}$ \\
\hline Predomínio tensional mão direita - diferença paralela egocífuga & 0,32 & 0,41 \\
\hline Predomínio tensional mão esquerda - diferença paralela egocífuga & 0,31 & 0,42 \\
\hline Predomínio tensional mão direita - diferença paralela egocípeta & 0,32 & 0,41 \\
\hline Predomínio tensional mão esquerda - diferença paralela egocípeta & 0,20 & 0,49 \\
\hline Emotividade mão direita DSv - Us & 0,19 & 0,53 \\
\hline Emotividade mão direita DSv - cadeias vert. ascendente & 0,19 & 0,54 \\
\hline \multicolumn{3}{|l|}{ Fator $7(\alpha=0,65)$} \\
\hline Traçado & Correlação item-fator & $\begin{array}{c}\alpha \text { se o item fosse } \\
\text { deletado }\end{array}$ \\
\hline Reação vivencial mão direita DSs - Us & 0,41 & 0,60 \\
\hline Reação vivencial mão direita DSs - lineograma & 0,39 & 0,60 \\
\hline Reação vivencial mão direita DSs - cadeias sag. egocípeto & 0,47 & 0,58 \\
\hline Reação vivencial mão direita DSs - cadeias sag. egocífugo & 0,39 & 0,60 \\
\hline Reação vivencial mão direita DSs - DPh lineograma & 0,33 & 0,62 \\
\hline Emotividade mão direita DSv - cadeias vert. descendente & 0,22 & 0,64 \\
\hline Reação vivencial mão direita DSs - zig egocípeto & 0,21 & 0,65 \\
\hline Reação vivencial mão direita DSs - paralelas egocífugo & 0,21 & 0,64 \\
\hline
\end{tabular}


Tabela 3

Cargas Fatoriais por meio da Análise Fatorial pelos Principais Eixos Fatoriais com Rotação Oblimin e Valores do Coeficiente Alfa

\begin{tabular}{|c|c|c|c|c|c|c|c|}
\hline Fatores & 1 & 2 & 3 & 4 & 5 & 6 & 7 \\
\hline Dimensão tensional mão direita - zig máx. egocípeto & 0,88 & & & & & & \\
\hline Dimensão tensional mão direita - zig máx. egocífugo & 0,86 & & & & & & \\
\hline Dimensão tensional mão esquerda - zig máx. egocípeto & 0,84 & & & & & & \\
\hline Dimensão tensional mão direita - zig min. egocífugo & 0,78 & & & & & & \\
\hline Dimensão tensional mão direita - zig min. egocípeto & 0,77 & & & & & & \\
\hline Dimensão tensional mão esquerda - zig máx. egocífugo & 0,76 & & & & & & \\
\hline Dimensão tensional mão esquerda - zig min. egocípeto & 0,70 & 0,33 & & & & & \\
\hline Dimensão tensional mão esquerda - zig min. egocífugo & 0,69 & 0,38 & & & & & \\
\hline Predomínio tensional mão direita - diferença zig egocífugo & 0,63 & & & & & & \\
\hline Predomínio tensional mão esquerda - diferença zig egocípeto & 0,55 & & & & & & \\
\hline Predomínio tensional mão esquerda - diferença zig egocífugo & 0,55 & & & & & 0,35 & \\
\hline Predomínio tensional mão direita - diferença zig egocípeto & 0,48 & & & & & 0,39 & \\
\hline Dimensão tensional mão esquerda - paralela min. egocípeta & & 0,84 & & & & & \\
\hline Dimensão tensional mão direita - paralela min. egocífuga & & 0,79 & & & & & \\
\hline Dimensão tensional mão direita - paralela min. egocípeta & & 0,79 & & & & & \\
\hline Dimensão tensional mão esquerda - paralela min. egocífuga & & 0,78 & & & & & \\
\hline Dimensão tensional mão direita - paralela máx. egocípeta & & 0,77 & & & & & \\
\hline Dimensão tensional mão esquerda - paralela máx. egocípeta & & 0,75 & & & & & \\
\hline Dimensão tensional mão esquerda - paralela máx. egocífuga & & 0,72 & & & & 0,40 & \\
\hline Dimensão tensional mão direita - paralela máx. egocífuga & & 0,70 & & & & & \\
\hline Dimensão tensional mão direita - lineograma & & 0,63 & & & & & \\
\hline Dimensão tensional mão esquerda - lineograma & & 0,62 & & & & & \\
\hline Agressividade mão direita DSh - lineograma & & & 0,60 & & & & \\
\hline Agressividade mão direita DPs - paralelas & & & 0,59 & & & & \\
\hline Agressividade mão esquerda DPs - cadeias & & & 0,59 & & & & \\
\hline Agressividade mão direita DPs - zig-zag & & & 0,58 & & & & \\
\hline Agressividade mão direita DPs - cadeias & & & 0,55 & & & & \\
\hline Agressividade mão esquerda DPs - lineograma & & & 0,55 & & & & \\
\hline Agressividade mão esquerda DPs - zig-zag & & & 0,54 & & & & \\
\hline Agressividade mão esquerda DSh - lineograma & & & 0,54 & & & & \\
\hline Agressividade mão direita DPs - Us & & & 0,54 & & & & \\
\hline Agressividade mão direita DPs - lineograma & & & 0,54 & & & & \\
\hline Agressividade mão esquerda DPs - Us & & & 0,53 & & & & \\
\hline Agressividade mão esquerda DPs - paralelas & & & 0,50 & & & & \\
\hline Tônus vital mão esquerda $\mathrm{DPv}$ - círculos & & & & 0,66 & & & \\
\hline Tônus vital mão direita $\mathrm{DPv}$ - Us & & & & 0,62 & & & \\
\hline Tônus vital mão esquerda $\mathrm{DPv}$ - lineograma & & & & 0,62 & & & \\
\hline Tônus vital mão direita $\mathrm{DPv}$ - lineograma & & & & 0,61 & & & \\
\hline Tônus vital mão esquerda $\mathrm{DPv}$ - Us & & & & 0,61 & & & \\
\hline Tônus vital mão direita $\mathrm{DPv}$ - círculos & & & & 0,59 & & & \\
\hline
\end{tabular}


Tabela 3

Cargas Fatoriais por meio da Análise Fatorial pelos Principais Eixos Fatoriais com Rotação Oblimin e Valores do Coeficiente Alfa (Continuação)

\begin{tabular}{|c|c|c|c|c|c|c|c|}
\hline Fatores & 1 & 2 & 3 & 4 & 5 & 6 & 7 \\
\hline Tônus vital mão esquerda DPv - cadeias & & & & 0,43 & & & \\
\hline Tônus vital mão direita $\mathrm{DPv}$ - cadeias & & & & 0,42 & & & \\
\hline Tônus vital mão direita DPv - escadas & & & & 0,34 & & & \\
\hline Tônus vital mão esquerda $\mathrm{DPv}$ - escadas & & & & 0,32 & & & \\
\hline Reação vivencial mão esquerda DSs - paralelas egocífugo & & & & & 0,63 & & \\
\hline Reação vivencial mão esquerda DSs - Us & & & & & 0,61 & & \\
\hline Reação vivencial mão esquerda DPh - lineograma & & & & & 0,58 & & \\
\hline Reação vivencial mão esquerda DSs - cadeias sag. egocífugo & & & & & 0,57 & & \\
\hline Reação vivencial mão esquerda DSs - paralelas egocípeto & & & & & 0,55 & & \\
\hline Reação vivencial mão esquerda DSs - cadeias sag. egocípeto & & & & & 0,51 & & \\
\hline Reação vivencial mão esquerda DSs - Lineograma & & & & & 0,49 & & \\
\hline Reação vivencial mão esquerda DSs - zig egocífugo & & & & & 0,40 & & \\
\hline Reação vivencial mão esquerda DSs - zig egocípeto & & & & & 0,33 & & \\
\hline Predomínio tensional mão direita - diferença paralela egocífuga & & & & & & 0,59 & \\
\hline Predomínio tensional mão esquerda - diferença paralela egocífuga & & & & & & 0,59 & \\
\hline Predomínio tensional mão direita - diferença paralela egocípeta & & & & & & 0,55 & \\
\hline Predomínio tensional mão esquerda - diferença paralela egocípeta & & & & & & 0,44 & \\
\hline Reação vivencial mão direita DSs - lineograma & & & & & & & 0,64 \\
\hline Reação vivencial mão direita DSs - Us & & & & & & & 0,64 \\
\hline Reação vivencial mão direita DSs - cadeias sag. egocífugo & & & & & & & 0,56 \\
\hline Reação vivencial mão direita DSs - cadeias sag. egocípeto & & & & & & & 0,55 \\
\hline Reação vivencial mão direita DSs - DPh Lineograma & & & & & & & 0,47 \\
\hline Reação vivencial mão direita DSs - zig egocípeto & & & & & & & 0,41 \\
\hline Reação vivencial mão direita DSs - paralelas egocífugo & & & & & & & 0,36 \\
\hline Quantidade de traçados & 12 & 10 & 12 & 10 & 9 & 4 & 7 \\
\hline Coeficiente alfa & 0,92 & 0,91 & 0,81 & 0,75 & 0,68 & 0,57 & 0,64 \\
\hline Autovalor & 9,34 & 4,98 & 4,00 & 2,85 & 2,50 & 2,40 & 2,28 \\
\hline Variância explicada (\%) & 14,59 & 7,79 & 6,25 & 4,46 & 3,91 & 3,74 & 3,56 \\
\hline Total de Variância explicada (\%) & & & & 44,30 & & & \\
\hline
\end{tabular}

A dimensão Predomínio Tensional dividiu-se em dois fatores, sendo que o fator 1 reuniu itens relativos à diferença linear dos "zigs", enquanto no fator 6 foram agrupados os itens relativos às diferenças lineares das paralelas e média dos comprimentos lineares dos lineogramas. Tal fato já tinha sido observado no estudo de Vasconcelos (2010). Vale ressaltar que os traçados dos "zigs" são realizados com as duas mãos, simultaneamente, enquanto que os traçados das paralelas e dos lineogramas são realizados com uma mão de cada vez.
Ainda, o tamanho dos traçados é diferente, sendo que a referência do zig é de $10 \mathrm{~mm}$ e na paralela é de $50 \mathrm{~mm}$. Ou seja, a realização do "zig-zag" pressupõe maior controle sobre o traçado, uma vez que se trata de um traço menor, no qual as mãos trabalham simultaneamente $\mathrm{e}$ no sentido de ida e volta. Já nas paralelas, a realização do traçado exige que o avaliado tire o lápis do papel e o modelo de referência é maior, imprimindo menor controle sobre a atividade realizada. Nesse sentido, pode-se pensar que a diferença na realização desses traçados se 
refira a variáveis latentes diferentes. No entanto, o que resta saber é o que cada dimensão estaria avaliando; e essa resposta parece não ter resposta com base na explicação teórica dos traçados que o manual do teste sustenta.

Contudo, a despeito dessa observação e considerando o apresentado por Galland de Mira (1987), o fato de a dimensão Predomínio Tensional ter se agrupado junto aos itens da Dimensão Tensional pode ser explicado em função de que ambas as dimensões estão relacionadas ao tamanho do traçado e aos reflexos da inibição e da excitação que se manifestam pelas vias neuroelétricas. $\mathrm{Na}$ excitação, há uma liberação desmedida ou exagerada nas suas atitudes e atividades, identificada por meio do aumento do traçado. O contrário ocorre na inibição, e há uma tendência a realizar os traçados menores. Dessa forma, tanto a excitação quanto a inibição estão relacionadas aos comprimentos lineares de traçados do teste. O Predomínio Tensional, segundo Galland de Mira (1987, p. 90), "deriva do processo fisiológico dos reflexos de inibição e excitação". Considera-se impulsividade quando há um aumento na diferença do tamanho dos traçados, ou rigidez, quando ocorre uma diminuição nessa diferença. Desse modo, as duas dimensões encontram-se interligadas, o que pode ter influenciado no agrupamento de alguns traçados.

A dimensão Tônus Vital agrupou-se toda no fator 4, corroborando os achados de Martinez (2002), Baumgartl (2004), Ral, Sanzano e Martinez (2005), e Tous, Viadé e Muiños (2006; 2007), o que indica que os traçados dessa dimensão mensuram a mesma característica latente. De acordo com Mira y López (1979), essa característica é investigada a partir dos traçados realizados com a mesa na posição vertical, e a elação irá prevalecer quando houver uma sobreposição dos músculos elevadores sobre os depressores. Por sua vez, na depressão há um predomínio dos músculos depressores sobre os elevadores. Todos os traçados agrupados nesse fator são medidos por meio do DPv, exigindo do avaliado transpor o obstáculo da lei da gravidade que, naturalmente, age, favorecendo a sobreposição dos músculos depressores sobre os elevadores.

O fator 3 agrupou os itens relacionados à dimensão Agressividade, revelando carga fatorial expressiva, variando entre 0,50 e 0,60 . Este fator agrupou os itens dos DPs e DSh também nos estudos de Martinez (2002), Baumgartl (2004), Ral, Sanzano e Martinez (2005), Tous, Viadé e Muiños (2006, 2007), Vasconcelos (2010) e Pasquali e Tróccolli (2014). A agressividade foi a única dimensão confirmada em todas as pesquisas com o teste. Para Mira y López (1979), a agressividade é a força que propulsiona o indivíduo a uma atitude de afirmação e domínio de si mesmo perante uma situação. Nesse fator, os itens do teste que são medidos pelos desvios primários na posição sagital e os desvios secundários horizontais foram agrupados, revelando que todos mensuram a mesma característica.

Já a Reação Vivencial dividiu-se em dois fatores, sendo agrupados os itens referentes à mão esquerda no fator 5 e os itens da mão direita no fator 7. O mesmo ocorreu na investigação realizada por Ral, Sanzano e Martinez (2005), Tous, Viadé e Muiños (2006, 2007), Vasconcelos (2010) e Pasquali e Tróccoli (2014). Nessa dimensão, o sujeito pode apresentar extratensão ou intratensão. $\mathrm{Na}$ intratensão, a energia psíquica é direcionada para si e, nesse caso, prevalecem os músculos adutores. Já na extratensão, a energia psíquica é direcionada para o meio e prevalecem os músculos abdutores em detrimento dos adutores. Considerando a teoria da dissociação miocinética, na qual os dois hemisférios cerebrais revelam características distintas (estruturais relativos à mão dominada, ou situacionais relativos à mão dominante), o agrupamento dos itens de cada mão em dois fatores distintos corrobora tal teoria. A ocorrência da distribuição em dois fatores pode estar relacionada à incoerência intrapsíquica, ou seja, um ajuste pobre entre os dados constitucionais e os atuais, dado esperado segundo o pressuposto teórico de Mira y López (1979).

Por fim, os itens relacionados à Emotividade não foram agrupados em um único fator, sendo eliminados na segunda análise em função de os itens terem sido encontrados nos fatores 5, 6 e 7, relativos à Reação Vivencial e Predomínio Tensional. Tais achados corroboram os resultados das análises realizadas por Baumgartl (2004). Ainda, Ral, Sanzano e Martinez (2005), Tous, Viadé e Muiños (2006) e Vasconcelos (2010), identificaram o agrupamento dos itens de emotividade com os itens de reação vivencial, separados em fatores para a mão esquerda e direita. $\mathrm{O}$ resultado aqui observado não é congruente com as propostas de Mira y López (1979), Galland de Mira (1987) e Pasquali e Tróccoli (2014). De acordo com Galland de Mira (1987), a emotividade está relacionada com a afetividade, e sendo assim, as características de personalidade supostamente medidas pelo PMK perpassam pela emotividade, o que possivelmente faz com que os itens desta dimensão se misturem a outros itens do teste, relativos a fatores diversos. Assim como em outras explicações para possíveis resultados que diferem do esperado no 
PMK, embora se possa considerar que a resposta seja plausível, ela está longe de demonstrar o quê, de fato, está se avaliando em uma ou em outra dimensão.

Resumindo, no que se refere à estrutura alcançada neste estudo e fazendo o contraponto com a literatura recuperada, fica evidente que a estrutura do teste não se mantém a mesma nos estudos realizados com o PMK, embora possam existir algumas semelhanças entre elas. Tal fato evidencia a necessidade de atualizar as bases teóricas que fundamentam o instrumento, pois existe a possibilidade do PMK não estar medindo as características de personalidade que se propõe, e pelas quais se tornou amplamente utilizado e difundido. Assim sendo, é possível questionar a base teórica que sustenta o teste, uma vez que, a estrutura fatorial do instrumento não se mantém estável nas pesquisas realizadas. Com base nesses aspectos é que se podem tecer as considerações mencionadas no início da discussão.

A primeira dúvida que vem à tona se refere à confiança que o PMK passa para o usuário da técnica. Pelos dados obtidos neste estudo e pela recuperação bibliográfica dos estudos sobre sua estrutura interna, pode-se pensar que os itens do teste estejam acessando construtos que não são referentes às características supostamente medidas pelo instrumento. Esse fato implica em questões éticas, pois a utilização do PMK com as fragilidades encontradas pode comprometer os resultados de uma avaliação psicológica de qualidade. Com isso, ressalta-se a necessidade de pesquisas que investiguem em profundidade a fundamentação teórica que envolve esta técnica.

Pensar em um teste utilizado no processo para obtenção da $\mathrm{CNH}$, em processos seletivos da polícia militar, em diversos concursos públicos para diferentes cargos, em avaliações do poder judiciário, e em vários outros contextos; e que aparentemente não sustenta claramente sua estrutura proposta é, no mínimo, preocupante. Também preocupante pode ser considerado o fato de os psicólogos que trabalham com avaliação psicológica compulsória utilizarem o teste sem nenhum questionamento.

Pasquali e Tróccoli (2014) afirmam que as conclusões de Sisto (2010) não são pertinentes para a versão do manual apresentado em 2014, e que valeriam apenas para os dados fornecidos pelo manual de 2004. Nesse sentido, importante lembrar que em 2012 a Comissão Consultiva do SATEPSI mencionava que o teste não apresentava uma fundamentação teórica consistente, e que isso impossibilitava a compreensão da relação entre as emoções e os movimentos musculares. Atualmente, o PMK recebeu novamente parecer favorável para sua utilização profissional, mas ao que parece essa resposta continua sem ser dada à comunidade científica, visto que não fica claro o porquê de as considerações tecidas por Sisto (2010) não serem ser também plausíveis para a versão atual do instrumento.

Por fim, e ainda refletindo sobre as considerações realizadas por Sisto em 2010, quando colocava em dúvida "o critério usado pelo Conselho Federal de Psicologia para avaliar que o PMK possui alguma evidência de validade brasileira, conseguida nos últimos anos. Ou algum estudo brasileiro ou estrangeiro" (p. 149), nos parece que naquela ocasião tal crítica não procedia, pois, o manual do teste tinha sido avaliado sob a ótica inicial do Sistema de Avaliação de Testes Psicológicos, que entre 2001 e 2003 foi construindo os critérios mínimos para considerar um teste favorável para uso profissional. No entanto, a afirmação realizada pelo autor parece sim ainda fazer sentido atualmente.

\section{Referências}

Bardella, J. G., Costa, R. C., Esteves, C., \& Alves, I. C. B. (2003). Estabilidade temporal do PMK em uma amostra de vigilantes. Boletim de Psicologia, 53(119), 201-214.

Baumgartl, V. O. (2004). Evidências de validade do BPR-5, o BFM-1 e PMK em eletricitários (Dissertação de mestrado). Universidade São Francisco, Itatiba, S. P.

Bessa, P. P. (1952). Ainda a validade do Psicodiagnóstico Miocinético. Revista da Faculdade de Direito da UFMG, 4, 182-196.

Bessa, P. P., \& Schwarztein, S. J. (1951). Uma pesquisa sobre a validade do PMK. Revista da Faculdade de Direito da UFMG, 3, 205-225.

Conselho Federal de Psicologia (2003). Resolução CFP 002/2003. Recuperado de http://www.pol.org.br

Conselho Federal de Psicologia (2012). Nota do CFP em resposta ao processo de avaliação do Teste PMK. Recuperado de http://www2.pol.org.br/boletins/2012/ polnews_20120518.html.

Galland de Mira, A. M. (1987). Psicodiagnóstico Miocinético. São Paulo: Vetor.

Hair, J. F., Anderson, R. E., Tatham, R. L., \& Black, W. C. (2005). Análise multivariada de dados. Porto Alegre: Bookman. 
Martinez, R. M. (2002). El Psicodiagóstico Miokinético: Desarrollo, descripción y análisis factorial confirmatorio (Tese de doutorado). Universitat de Barcelona, Barcelona, Espanha.

Mira y López, E. (1951). Étude sur la validité du Test Psychodignostic Miokinétique. L' Anné Psychologique, 50, 575-584.

Mira y López, E. (1979). Psicodiagnóstico Miokinético. Buenos Aires: Paidós.

Pasquali, L. (2003). Psicometria: Teoria dos testes na Psicologia e na Educaşão. Petrópolis: Vozes.

Pasquali, L., \& Trócoli, B. T. (2014). Parâmetros psicométricos do Psicodiagnóstico Miocinético. Em Galland de Mira, A. M. Psicodiagnóstico Miocinético (5 ${ }^{\mathrm{a}}$ ed). São Paulo: Vetor.

Quintela, G. (1977). A validade do psicotécnico na seleção de motoristas, quando cientificamente aplicado e interpretado o psicodiagnóstico miocinético de Mira y López. Arquivos Brasileiros de Psicologia Aplicada, 29(3), 137-142.

Ral, J. M. T., Sanzano, A. V., \& Martinez, R. M. (2005). Normalización de los lineogramas del PMK para Barcelona y su comparación con Recife. PSIC: Revista da Vetor Editora, 6(1), 17-26.
Rennes, P. (1965). Une analyse factorielle du PMK de Mira y López. Revue de Psychologie Apliquée, 15(3), 149-177.

Sisto, F. F. (2010). Uma análise das evidências de validade brasileiras do PMK. Psico-USF, 15(2), 141-149.

Tabachnick, B. G., \& Fidell, L. S. (2001).Using Multivariate Statistics. Needham Heights, MA: Allyn \& Bacon.

Tous, J. M. R., Viadé, A., \& Muiños, R. (2006). Comparación de los lineogramas del PMK-RD con los lineogramas del PMK. Psicologia: Pesquisa \& Trânsito, 2(1), 1-8.

Tous, M. J, Viadé, A., \& Muiños, R. (2007). Validez estructural de los lineogramas del psicodiagnóstico miokinético, revisado y digitalizado (PMK-RD). Psicothema, 19(2), 350-356.

Vasconcelos, A. G. (2010). Evidências de validade preditiva de medidas psicológicas em relação ao desempenho no trabalho: Um estudo de caso em uma organização militar (Dissertação de mestrado). Universidade Federal de Minas Gerais, Belo Horizonte.

Recebido 29/01/2015

Reformulado 20/10/2015

Aceito 01/02/2016

Sobre os autores:

Eni Ribeiro da Silva é doutora em Psicologia pelo Programa de Pós-Graduação Stricto Sensu em Psicologia da Universidade São Francisco e docente do curso de Psicologia da Pontifícia Universidade Católica de Minas Gerais.

E-mail:psicoeni@ig.com.br

Fabián J. M. Rueda é doutor em Psicologia pelo Programa de Pós-Graduação Stricto Sensu em Psicologia da Universidade São Francisco e docente do mesmo Programa. Atualmente é bolsista produtividade do CNPq. E-mail: fabian.rueda@usf.edu.br

Contato com os autores:

Rua Waldemar César da Silveira, 105, Vl. Cura D'Ars (SWIFT)

CEP: $13045-510$

Campinas-SP, Brasil 